\title{
Bronchoalveolar lavage fluid cell counts in cryptogenic fibrosing alveolitis and their relation to therapy
}

\author{
P L HASLAM, C W G TURTON, A LUKOSZEK, A J SALSBURY, A DEWAR, J V COLLINS \\ AND M TURNER-WARWICK
}

From the Department of Medicine, Cardiothoracic Institute, Brompton Hospital, London

ABSTRACT Bronchoalveolar lavage was used to sample inflammatory cells from the lungs of $51 \stackrel{\omega}{\omega}$ patients with cryptogenic fibrosing alveolitis (CFA) (24 smokers, 12 ex-smokers, and 15 non-smokers). N The smokers with CFA have been compared with 15 smoking control subjects in whom there was응 no radiographic abnormality or clinical evidence of chronic bronchitis. Significantly lower volumes of lavage fluid were recovered from the smokers with CFA $(\mathrm{p}<0.001)$ and the fluid contained lower 3 percentages of macrophages $(\mathrm{p}<0.01)$, reflecting increased percentages of eosinophils $(\mathrm{p}<0.001)^{2}$ and neutrophils $(\mathrm{p}<0.01)$. Similar changes were seen in the ex-smokers and non-smokers. There was $\mathbb{\infty}_{\infty}$ also an increase in the percentages of lymphocytes when the whole group of CFA patients was. compared with the control subjects $(\mathrm{p} \leqslant 0.05)$. No significant differences were found when patients with "lone" CFA were compared with those having associated systemic disease. The only feature distinguishing smokers from non-smokers with CFA was the presence of pigmented cytoplasmic inclusions in the macrophages from the smokers $(\mathrm{p}<0.001)$. However, there were lower numbers of $\frac{\mathcal{Q}}{\mathcal{O}}$ pigmented macrophages in the smoking CFA patients by comparison with the control subjects suggesting either a change in phagocytic capacity or turnover rate in this disease. Profiles of $\overrightarrow{\vec{O}}$ differential cell counts in individual patients showed that increases of eosinophils over $3 \%$ or neutrophils over $4 \%$ or both with lymphocyte counts of less than $11 \%$ related to a poor clinicalo response to corticosteroids, but lymphocyte percentages greater than $11 \%$ related to improvement $(\mathrm{p}<0.05)$.

Earlier studies have shown that the cell populations of bronchoalveolar lavage fluids in normal volunteers are mainly alveolar macrophages with small numbers of lymphocytes. ${ }^{12}$ The influence of smoking in normal volunteers has demonstrated significantly higher total cell yields with increased percentages of macrophages and decreased lymphocytes. ${ }^{13}$ Thus the influence of smoking must be taken into account in any clinical study.

Lung lavage samples obtained from patients with interstitial pulmonary fibrosis (IPF) have been compared with those from normal healthy volunteers and control patients without peripheral lung disease. ${ }^{45}$ In IPF percentages of alveolar macrophages were reduced reflecting an increase in neutrophils and eosinophils. Smoking did not influence these findings but neutrophil percentages were lower in the patients receiving

Address for reprint requests: Dr PL Haslam, Department of Medicine, Cardiothoracic Institute, Brompton Hospital, Fulham Road, London SW3 6HP. corticosteroid treatment.

In the present study we consider patients with cryptogenic fibrosing alveolitis (CFA) in whom the clinical features are very similar to cases in $\mathrm{O}$ other reports described as interstitial pulmonary? fibrosis. We extend previous observations ando compare patients with and without associated systemic disorders. We also relate differentialos lavage cell counts to the progression rate of dis- $N$ ease and the clinical response to corticosteroid N treatment.

\section{Methods}

PATIENTS WITH CRYPTOGENIC

FIBROSING ALVEOLITIS (CFA)

We studied 51 patients with clinical, radiological, and physiological evidence of cryptogenic fibros- $\frac{\vec{\phi}}{\mathrm{D}}$ ing alveolitis. The diagnostic criteria were breath- $\frac{\varrho}{\sigma}$ lessness, widespread crackles especially over the lower lobes of the lungs, widespread shadowingo on the chest radiograph, and a restrictive ventila 
tory defect without airways obstruction. Other known causes of chronic widespread lung shadowing such as inhaled inorganic or organic dusts or sarcoidosis were reasonably excluded. Histological confirmation of the diagnosis was available in 30 cases. Thirty-six of 51 patients had only the lung disorder, and included 29 men and seven women (mean age 56 years $\pm 9 \mathrm{SD}$, range 33-79 yr). Twenty-six patients were untreated at the time of lung lavage but 10 were receiving treatment with immunosuppressive or anti-inflammatory drugs-prednisone in nine and prednisone and penicillamine in one. Nineteen were smokers, 10 ex-smokers, and seven nonsmokers.

The remaining 15 of the 51 patients had the lung disorder in association with connective tissue disorders of other systems, and included 10 men and five women (mean age 47 years \pm 11 $\mathrm{SD}$, range 29-64 yr). Five were untreated at the time of lung lavage and included two with associated systemic sclerosis, one with systemic lupus erythematosus, one with dermatomyositis, and one with thyroiditis. The remaining 10 patients were receiving treatment (four prednisone, two prednisone and penicillamine, one prednisone together with cyclophosphamide, cyproheptidine, and colchicine, two cyclophosphamide, cyproheptidine, and colchicine, and one prednisone and azathioprine). Three of these patients had associated rheumatoid arthritis (RA), four systemic sclerosis, two dermatomyositis, and one SLE, Raynaud's and Sjogren's syndrome. Five of the 15 patients with associated disorders were smokers, two ex-smokers, and eight non-smokers.

Rate of natural progression was assessed for the 31 untreated patients by questioning them at the time of admission for lavage about their breathlessness over the previous six to 12 months. In 16 cases it was also possible to assess post-lavage progression from clinical, radiographic, and physiological follow-up over a further year when they remained untreated.

Response to treatment with prednisone or other immunosuppressive and anti-inflammatory drugs was assessed from clinical, radiographic, and physiological post-treatment follow-up over a period of at least 12 months to determine both initial (one month) and maintained (12 months) response. The criteria for response were either maintained subjective clinical improvement, or maintained objective improvement in physiology $(10 \%$ increase in either VC or Kco as per cent predicted) or maintained objective change in the chest radiographic profusion score using the International Union Against Cancer scoring system, ${ }^{6}$ and paired film analysis.

SMOKING PATIENT CONTROL SUBJECTS

Fifteen patients were studied who were undergoing routine bronchoscopy for suspected bronchial carcinoma either because of haemoptysis or contralateral pulmonary shadowing. In all these cases the lung lavaged was radiographically normal. None had physiological evidence of airways obstruction, and none had chronic bronchitis fulfilling the Medical Research Council criteria. ${ }^{7}$ All were cigarette smokers in amounts varying from an occasional one to 100 cigarettes a day. Eleven were men and four women (mean age 51 years, $15 \mathrm{SD}$, range 22-75 yr). For ethical reasons lavage was not performed in normal healthy smoking or non-smoking volunteers. Published data on normal non-smokers are scant and mainly relate to younger adults, but have been referred to where possible.

\section{BRONCHOALVEOLAR LAVAGE}

The method used and its acceptability to patients are described in detail elsewhere. ${ }^{8}$ In brief, lavage was performed after premedication with atropine and omnopon under local anaesthetic using lignocaine through an Olympus fibreoptic bronchoscope, and all patients received supplementary oxygen. The tip of the bronchoscope was wedged into the lateral basal segment of the right lower lobe and $60 \mathrm{ml}$ aliquots of sterile normal saline, buffered to $\mathrm{pH} 7 \cdot 0$ with $8.4 \%$ sodium bicarbonate were introduced and aspirated. The mean fluid volume introduced was $397 \mathrm{ml} \pm 76 \mathrm{SD}$ (range $120-540 \mathrm{ml}$ ), the mean volume of fluid retrieved was $114 \mathrm{ml} \pm 27 \mathrm{SD}$ (range 60-150 ml), and the mean percentage fluid recovery was $29 \%$ \pm 8 SD (range 10-42\%). The aspirated fluid was collected into a sterile siliconised graduated container and transported on ice immediately to the laboratory. Technical procedures were performed using siliconised or plastic utensils to minimise loss of cells by adherence, and sterile techniques were observed throughout.

TOTAL COUNTING OF CELLS IN LAVAGE FLUID The total volume of aspirated fluid was noted. Cells in the fluid were collected by immediate low speed centrifugation at $300 \mathrm{~g}$ for five minutes at $4^{\circ} \mathrm{C}$ and washed three times with cold minimum essential medium (MEM) containing 25 mM Hepes buffer (Gibco Bio-cult, code 237). The cells were counted in an Improved Neubauer Counting Chamber using $1 \%$ methyl violet in $1 \%$ acetic acid as the counting fluid. Total cell counts were expressed either as the overall 
total of cells obtained from the aspirated fluid, or as the total number of cells per $\mathrm{ml}$ of the aspirated fluid.

\section{DIFFERENTIAL COUNTING OF CELLS}

\section{IN LAVAGE FLUIDS}

For morphological examination of lavage cells, slide preparations were made in a Shandon Cytocentrifuge using Chance $0.8-1.0 \mathrm{~mm}$ thickness slides and $100 \mu 1$ aliquots of the lavage cell suspensions adjusted to $1.25 \times 10^{6}$ cells per $\mathrm{ml}$ in MEM, and spinning at $300 \mathrm{~g}$ for 10 minutes. After fixation in methanol, the preparations were stained with May Grünwald stain as conventionally used for differential white blood cell counting and mounted in DPX under Chance No 0 cover slips. Slides were examined separately by two observers and a differential counting scheme devised according to the range of morphological variants identified (fig 1). Differential counts were made from a total count of 500 cells, using $\times 25$ and $\times 54$ objectives and $\times 12.5$ periplan eyepieces. "Macrophages" were identified having variable appearances including large and intermediate-sized mononuclear cells with clear or foamy cytoplasm or densely pigmented cytoplasmic inclusions, and multinucleate cells. Electron microscopy on all samples confirmed that the great majority of these variants had the characteristics of macrophages rather than those of pneumocytes, Lymphocyte variants included $\overrightarrow{\vec{s}}$ small and large lymphocytes and occasionally $\overrightarrow{0}$ variants with nuclear indentation. Polymorpho- $\frac{C}{0}$ nuclear leucocytes (neutrophils) and eosinophils $\overline{\bar{\sigma}}$ were also identified. Ciliated and squamous $\vec{\Phi}$ epithelial cells were occasionally seen, and in very rare instances mast cells and plasma cells. क Other features, not included in differential count- $\vec{O}$ ing which were recorded if observed were de- $\overrightarrow{\vec{\omega}}$ generate cells, erythrocytes, bacteria, dust fibres, $\stackrel{\omega}{\rho}$ and mucus. In very rare cases mucus was present $\overrightarrow{\vec{x}}$ in such large amounts that slide preparations $\underset{\omega}{x}$ could not be made in the usual way. In such on cases washed cell suspensions were vortexed with an equal volume of a 1 in 10 dilution of $\underset{\infty}{N}$ "Sputolysin" (Calbiochem Ltd) for 20 minutes, $ᄋ$

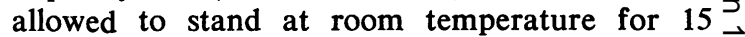
minutes, washed twice in MEM, and readjusted $z$ to a $1.25 \times 10^{6}$ cell suspension. Cytocentrifuge preparations were then made and stained as $\vec{\theta}$ above. "Sputolysin" pre-treatment could not be $\propto$ demonstrated to have any deleterious effect on differential counting in control studies.

\section{STATISTICAL METHODS}

Ranking tests were used for group comparisons involving quantitative data. For comparisons $\stackrel{\mathbb{Q}}{\square}$ limited to groups of two the Mann-Whitney $U \overrightarrow{0}$ test was used, and for comparisons involving $\exists$ three groups-for example, smokers, ex-smokers,
Fig 1 Examples of methanol-fixed, May-Grunwald-stained cytocentrifuge preparations of cells from lavage fluids. Original magnification $\times 346$.

(a) Predominance of "macrophages" with densely pigmented cytoplasmic inclusions in a smoking control subject. (b) Macrophages without dense pigmentation in a non-smoker with CFA. (c) Macrophages together with lymphocytes in a patient with CFA. (d) Macrophages together with neutrophils in a patient with CFA.

(e) Macrophages together with neutrophils and eosinophils in a patient with $C F A$.

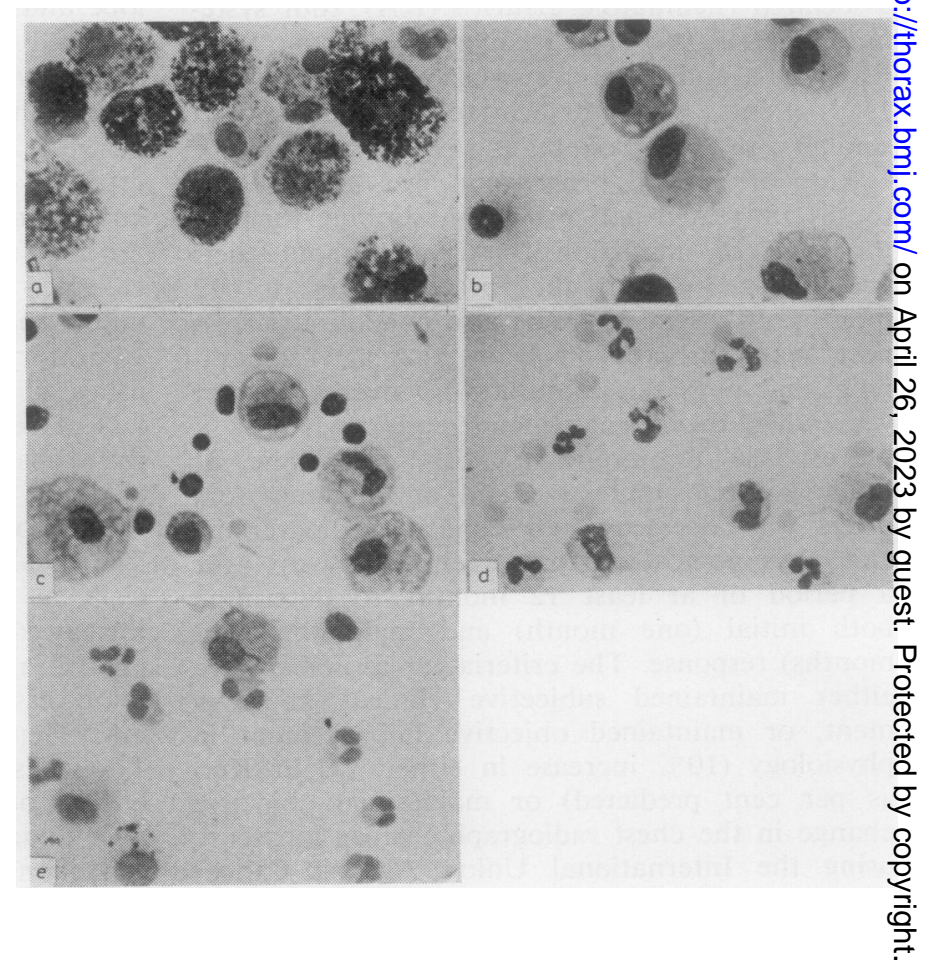


and non-smokers - Kruskal Wallis one-way analysis of variance by ranks was the method used. Correlations were tested using linear regression analysis. Means and absolute ranges are quoted in the results, but standard deviations are not given since most of the data are nonparametric.

\section{Results}

\section{LAVAGE FLUID RECOVERY}

There were lower percentages of fluid recovered from patients with "lone" CFA and similarly from those with associated disorders than from the smoking control subjects ( $p \leqslant 0.001$; fig 2 ). The mean percentage fluid recovery for the total patients with lone and associated systemic disorders was $27 \%$ (range $10-43 \%$ ) compared with a mean of $36 \%$ (range $26-54 \%$ ) for the smoking control subjects. Smoking and treatment within the CFA groups is also indicated in fig 2 and similar results for smokers, ex-smokers, and nonsmokers and for treated and untreated patients were confirmed in the statistical tests.

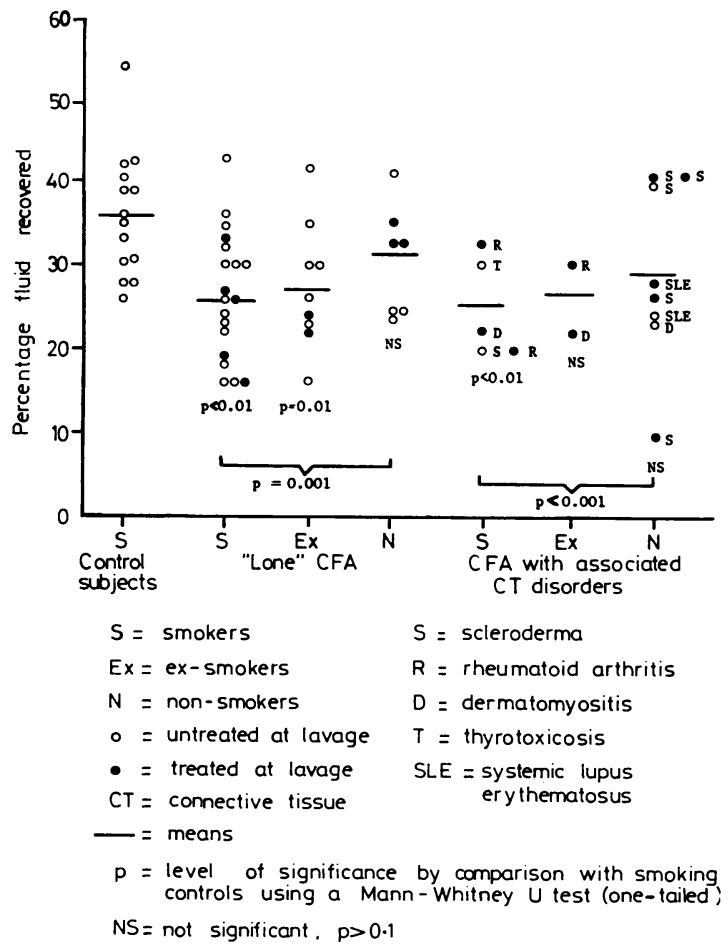

Fig 2 Percentages of lung lavage fluid recovered from patients with cryptogenic fibrosing alveolitis (CFA) compared with smoking control subjects without peripheral lung disease.
LAVAGE CELLS YIELDS

The mean volume of fluid recovered from smoking control subjects was $120 \mathrm{ml}$ (range 65-150 ml) containing a mean absolute total number of $61.59 \times 10^{6}$ nucleated cells (range 7.7-152.6 $\left.\times 10^{6}\right)$. The mean volume recovered from patients with lone CFA was $113 \mathrm{ml}$ (range 60$160 \mathrm{ml}$ ) containing a mean of $808 \times 10^{6}$ cells (range 3.3-492.6 $\times 10^{6}$ ), and from patients with CFA having associated connective tissue disorders was $113 \mathrm{ml}$ (range $50-150 \mathrm{ml}$ ) with a mean of $36.42 \times 10^{6}$ cells (range 6.4-102 $\times 10^{6}$ ). The variation in cell yields was independent of the variation in fluid recovery volumes ( $r=$ $0 \cdot 28$, NS).

There was a highly significant correlation between absolute total cell yields and cell yields per $\mathrm{ml}$ of lavage fluid recovered $(\mathrm{r}=0.98$, $\mathrm{p}<0.001$ ), and for comparative purposes yields have been expressed as total numbers of cells per $\mathrm{ml}$. The results are shown in fig 3. Cell yields were lower in CFA patients having associated disorders (mean $0.3 \times 10^{8}$, range 0.01-1.02 $\times$ $\left.10^{6}\right)$ than in the smoking control subjects (mean $0.53 \times 10^{5}$, range $\left.0.06-1.27 \times 10^{6}\right)(\mathrm{p}<0.05)$ but this reflected a significant trend towards lower cell yields in the non-smoking patients $(p=0.025)$. However, a general trend towards lower cell yields in non-smokers compared with smokers with CFA did not reach statistical significance. Cell yields in patients with lone CFA resembled those in the smoking control subjects, although two individuals were distinguished by inexplicably high cell yields (fig 3 ). There was no significant effect of treatment on cell yields within the CFA group.

DIFFERENTIAL COUNTS OF LAVAGE CELLS

Macrophages Differential count percentages of "macrophages" are shown in fig 4a. The counts include the range of "macrophage" appearances, but in every case the great majority were large mononuclear cells with clear or foamy cytoplasm. "Macrophage" counts were significantly lower in lone CFA (mean $71 \%$, range 19-96\%) and in CFA with associated disorders (mean $65 \%$, range $23-92 \%$ ), than in the smoking control subjects (mean $87 \%$, range $41-99 \%$ ), $p<0.01$ and $\mathrm{p}<0.001$ respectively). The decrease was apparent irrespective of smoking or treatment. Within the CFA group smokers had slightly higher macrophage counts than non-smokers as has been reported for normal volunteers, ${ }^{13}$ but unlike the normal situation this did not reach significance.

Lymphocytes Differential count percentages of 


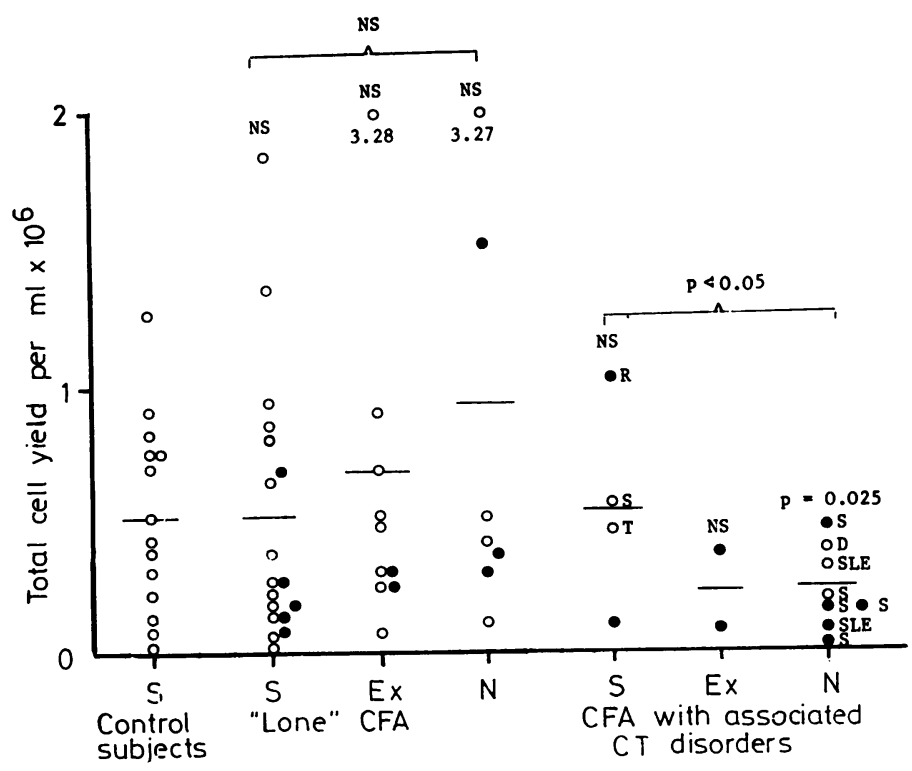

Fig 3 Total cell yields per $\mathrm{ml}$ of lung lavage fluid recovered from patients with cryptogenic fibrosing alveolitis compared with smoking control subjects without peripheral lung disease. Abbreviations and symbols as in fig 2.

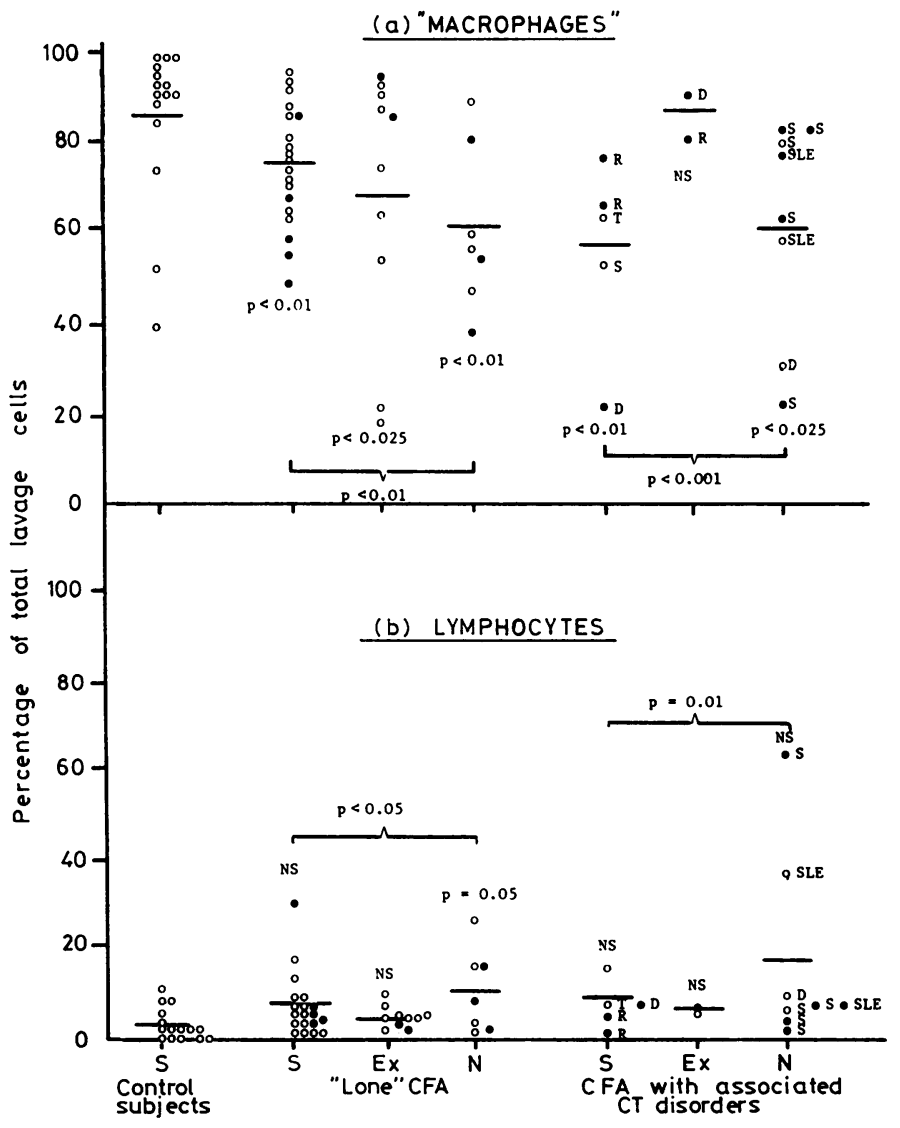

Fig 4 Differential count percentages of (a) macrophages and (b) lymphocytes in lung lavage fluids from patients with cryptogenic fibrosing alveolitis compared $\$$ with smoking control subjects without peripheral lung disease. Abbreviations and symbols as in fig 2. 
lymphocytes are shown in fig $4 \mathrm{~b}$. The majority were small or large lymphocytes and variants with marked nuclear indentation were extremely rare. A trend towards higher lymphocyte counts in patients with CFA compared with smoking control subjects only reached significance for the total CFA patients $(p<0.05$ for lone CFA; $\mathrm{p}=0.01$ for CFA with associated disorders) not for the smokers alone. The mean for the total with lone CFA was $6 \%$ (range $\mathbf{0 . 2}-30 \%$ ) and for those with associated disorders was $12 \%$ (range $0-65 \%$ ). The mean for the smoking control subjects was $3 \%$ (range $0.4-11 \%$ ) and for the total CFA smokers $7 \%$ (range 0-30\%). Four CFA smokers had counts above the $11 \%$ upper limit for the smoking control subjects. Lymphocyte counts were slightly higher for the total CFA non-smokers (mean 14\%, range 1-65\%), but within the CFA group the difference between non-smokers and smokers was not significant, and three of the 15 non-smoking patients had lymphocyte counts higher than the $20 \%$ upper limit reported for normal non-smokers. ${ }^{145}$ Counts were not significantly different in patients on and off treatment.

Neutrophils Differential count percentages of neutrophils are shown in fig $5 \mathrm{a}$. The majority of smoking control subjects had neutrophil counts less than $4 \%$ although three had higher counts. The mean neutrophil count for the controls was $6 \%$ (range $0 \cdot 2-36 \%$ ). By comparison, the counts for CFA were significantly increased irrespective of smoking or associated disease. The mean count for the total with lone CFA was $13 \%$ (range $0-43 \%) \quad(p<0.001$ compared with control subjects). The mean for the total with CFA and associated disorders was $13 \%$ (range $0.6-68 \%)(\mathrm{p}<0.01$ compared with control subjects). Of the patients with associated disorders, the two with the highest neutrophil counts $(36 \%$ and $68 \%)$ had dermatomyositis. Neutrophil counts for treated and untreated patients with CFA did not differ significantly.

Eosinophils Differential count percentages of eosinophils are shown in fig $5 \mathrm{~b}$. Eosinophils were very uncommon in the smoking control subjects (mean $0.3 \%$, range $0-2.4 \%$ ) but by contrast were increased above $2.4 \%$ in over half the patients
Fig 5 Differential count percentages of (a) neutrophils and (b) eosinophils in lung lavage fluids from patients with cryptogenic fibrosing alveolitis compared with smoking control subjects without peripheral lung disease. Abbreviations and symbols as in fig 2.

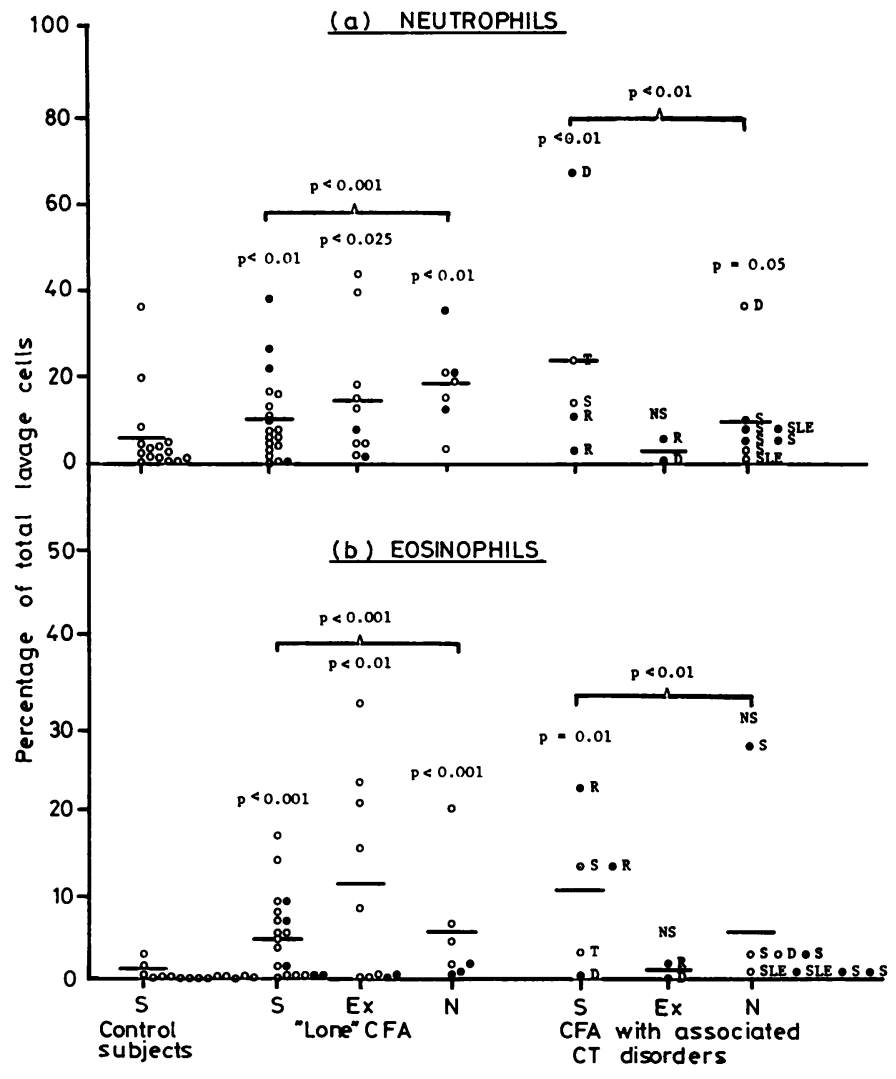


with CFA. The mean for the total patients with lone CFA was $6.2 \%$, range $0-31.5 \% \quad(p<0.001$ compared with control subjects) and the increase was significant irrespective of the smoking habit. The mean for the total patients with associated disorders was $5.9 \%$ (range $0-27.6 \%) \quad(p<0.01$ compared with control subjects) although this was only confirmed for the smokers. However, there was no significant influence of smoking in either CFA group. Eosinophil counts were significantly lower in treated (mean $2.1 \%$, range 0 to $8.6 \%$ ) than in untreated (mean $7.7 \%$, range $0-31.5 \%$ ) patients with lone CFA $(\mathrm{p}<0.025)$ but no significant effect of treatment was demonstrated in patients with associated disorders.

PERIPHERAL BLOOD EOSINOPHIL COUNTS IN CFA Only four (8\%) of the total 51 CFA patients in this study, including only two $(9 \%)$ of the 23 with lavage eosinophils increased above $3 \%$ had a peripheral blood eosinophil count greater than $0 \cdot 4 / \mathrm{nl}$ at the time of lavage. The peripheral blood white cell counts were normal in these four patients.

\section{DENSELY PIGMENTED MACROPHAGE CYTOPLASMIC}

INCLUSIONS

Numerous densely pigmented irregular inclusions were clearly visible in the cytoplasm of variable numbers of "macrophages" from smokers and ex-smokers, but this feature was very rare in non-smokers (fig 6). This correlation of increased

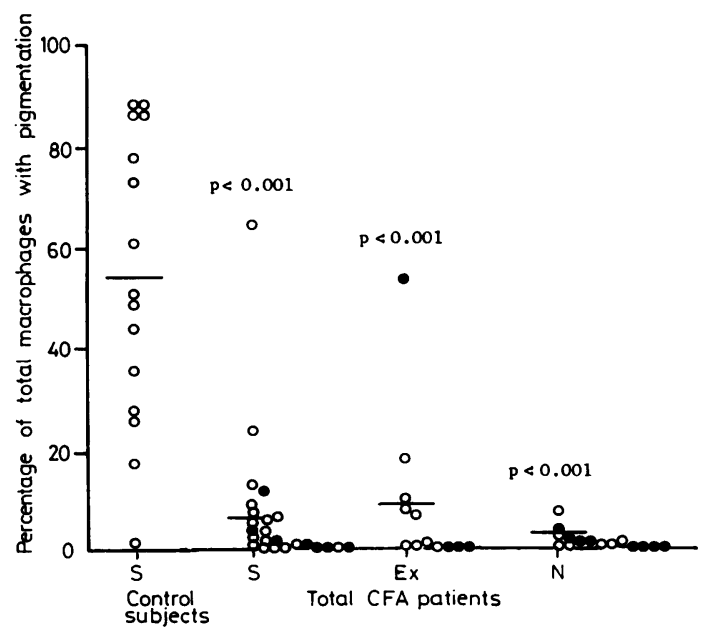

Fig 6 Percentages of total lavage macrophages with densely pigmented cytoplasmic inclusions in smokers, ex-smokers, and non-smokers with cryptogenic fibrosing alveolitis compared with smoking control subjects without peripheral lung disease. Abbreviations and symbols as in fig 2.

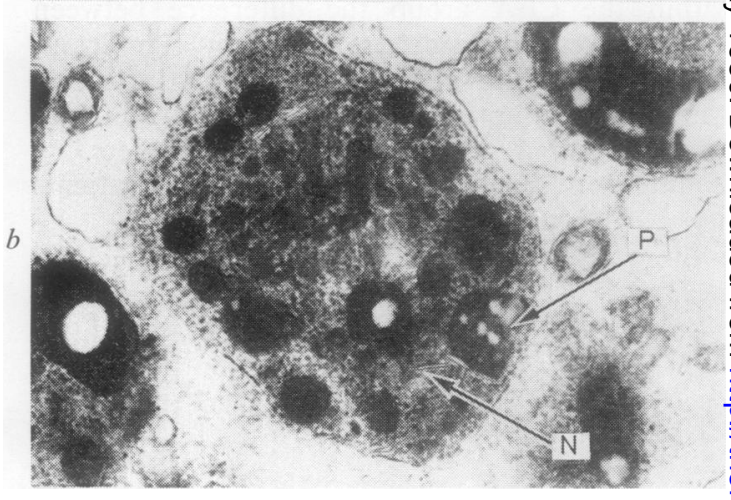

Fig 7 Electron-micrographs showing: (a) the typica议 macrophage appearance of large mononuclear cells in lavage fluids ( $L=$ lysosomes, $P=$ pseudopodia,

$N=$ nucleus, $M=$ mitochondria); (b) example of plate $-\frac{\delta}{-}$ like $(P)$ and needle-like $(N)$ inclusions within phagosome as seen in some macrophages from smokers and ex-smokers but not from non-smokers. Original magnifications $\times 7000$ and $\times 45000$ respectively.

percentages of pigmented macrophages with smoking was highly significant overall and in the CFA group $(p<0.001)$. The proportion of macro- $\omega$ phages with inclusions in the smoking controk subjects was not only significantly higher than in the non-smokers and ex-smokers with CFA but was also significantly higher than in the smokers $(\mathrm{p}<0.001)$. This difference was not explained by the numbers of cigarettes smoked. Electron $\mathbb{\mathbb { D }}^{+}$ micrographs of lavage macrophages from the $\frac{?}{\mathbb{Q}}$ smokers showed heavy electron-dense plate-like 2 and needle-like inclusions within the phago lysosomes not seen in the macrophages from the non-smokers (fig 7). 
PROFILES OF LAVAGE CELL COUNT INCREASES IN INDIVIDUAL CFA PATIENTS

The various combinations of increases in lavage lymphocytes, neutrophils, and eosinophils in individual CFA patients are shown in table 1. Increases were defined by reference to the upper limit of the absolute range for the smoking control group $(>11 \%$ for lymphocytes and $>3 \%$ for eosinophils by whole numbers). In the case of neutrophils, because of the markedly skew distribution of counts in our control subjects from three high values, levels exceeding $4 \%$ were accepted as increased; this value included all our other control subjects and is in line with the upper limit of neutrophils in normal volunteers. ${ }^{13}$ (In the absence of non-smoking control subjects, "Increase" does not necessarily imply abnormality).

Forty-seven (92\%) of the total 51 CFA patients had an increase in at least one inflammatory cell type. The most common patterns of increase were combined increases in neutrophils and eosinophils $(37 \%)$ or increases in neutrophils alone (31\%). Combined eosinophil-neutrophil increases were, however, notably the more common in patients with lone CFA and in patients untreated at lavage, while neutrophil increases only were notably more common in patients with associated extrapulmonary connective tissue disorders and in patients on treatment at lavage. Lymphocyte counts higher than $11 \%$ occurred in nine $(18 \%)$ of the total 51 patients, combined with neutrophil increases in four and with eosinophil as well as neutrophil increases in just two cases.

\section{RELATIONSHIP OF DIFFERENTIAL LAVAGE CELL} COUNTS TO RESPONSE TO PREDNISONE AND OTHER IMMUNOSUPPRESSIVE AND ANTI-INFLAMMATORY DRUGS IN CFA

The value of differential lavage cell counting in predicting maintained response to treatment was explored in 14 patients untreated at lavage but subsequently treated, and in 18 patients on treatment at the time of lavage. Full clinical, radiographic and physiological post-treatment followup was available for these patients to allow assessment of both initial and maintained response. The relationship of the levels of lavage cell counts to maintained response and drug regimens at the end of the follow-up period in these patients is shown in fig 8. Patients who responded to prednisone (fig 8a) had significantly decreased levels of lavage eosinophils compared with non-responders $(p=0.036)$. The trend towards higher levels of lymphocytes in the responders did not achieve statistical significance. The neutrophil levels were not by themselves useful in distinguishing responders from nonresponders. The profiles of lavage cell increases in individual patients (table 2) were important in showing a significant correlation of prednisone response with lavage lymphocyte counts higher than $11 \%$ irrespective of associated increases in neutrophils and eosinophils (six of eight responders), but of failure to respond with combined increases in neutrophils and eosinophils or increases in neutrophils without increases in lymphocytes (eight of nine non-responders) $(\mathrm{p}<0.05)$.

Patients who had failed to respond to prednisone or where prednisone was contraindicated and who were treated with cyclophosphamide, in some cases with various combinations of other drugs, are also considered in fig $8 \mathrm{~b}$ and in table 2 . Response to these drugs occurred in eight of the 15 patients and none had increased lavage lymphocyte counts (the patients with lymphocyte counts higher than $11 \%$ having been selected into prednisone responsive group). The lavage cell profiles showed that response to these drugs could be obtained in patients with combined increases in neutrophils and eosinophils, or increases in

Table 1 Profiles of lavage inflammatory cell increases in CFA

\begin{tabular}{|c|c|c|c|c|c|c|c|c|c|}
\hline \multirow[t]{2}{*}{ Patients } & & \multicolumn{7}{|c|}{ Number with increases in } & \multirow{2}{*}{$\begin{array}{l}\text { Total } \\
\text { with } \\
\text { ircreases }\end{array}$} \\
\hline & & $\begin{array}{l}\text { Neutrophils } \\
\text { only } \\
(>4 \%)\end{array}$ & $\begin{array}{l}\text { Eosinophils } \\
\text { only } \\
(>3 \%)\end{array}$ & $\begin{array}{l}\text { Neutrophils } \\
\text { and } \\
\text { eosinophils }\end{array}$ & $\begin{array}{l}\text { Lymphocytes } \\
\text { only } \\
(>11 \%)\end{array}$ & $\begin{array}{l}\text { Lymphocytes } \\
\text { and } \\
\text { neutrophils }\end{array}$ & $\begin{array}{l}\text { Lymphocytes } \\
\text { and } \\
\text { eosinophils }\end{array}$ & $\begin{array}{l}\text { Lymphocytes, } \\
\text { neutrophils } \\
\text { and } \\
\text { eosinophils }\end{array}$ & \\
\hline Lone & 36 & $\begin{array}{l}10 \\
(28\end{array}$ & $\begin{array}{l}2 \\
6\end{array}$ & $\begin{array}{l}16 \\
44\end{array}$ & $\begin{array}{l}2 \\
6\end{array}$ & $\begin{array}{l}3 \\
8\end{array}$ & $\begin{array}{l}\mathbf{0} \\
0\end{array}$ & $\begin{array}{l}1 \\
3\end{array}$ & $\begin{array}{l}34 \\
94 \%)\end{array}$ \\
\hline Systemic & 15 & $\begin{array}{l}6 \\
(40\end{array}$ & $\begin{array}{l}1 \\
7\end{array}$ & $\begin{array}{l}3 \\
20\end{array}$ & $\begin{array}{l}1 \\
7\end{array}$ & $\begin{array}{l}1 \\
7\end{array}$ & $\begin{array}{l}0 \\
0\end{array}$ & $\begin{array}{l}1 \\
7\end{array}$ & $\begin{array}{l}13 \% \\
87 \%\end{array}$ \\
\hline Untreated & 31 & $\begin{array}{l}7 \\
(23\end{array}$ & $\begin{array}{l}2 \\
6\end{array}$ & $\begin{array}{l}14 \\
45\end{array}$ & $\begin{array}{l}2 \\
6\end{array}$ & $\begin{array}{l}2 \\
6\end{array}$ & $\begin{array}{l}\mathbf{0} \\
\mathbf{0}\end{array}$ & $\begin{array}{l}2 \\
6\end{array}$ & $\begin{array}{l}29 \\
94 \%)\end{array}$ \\
\hline On treatment & 20 & $\begin{array}{l}9 \\
(45\end{array}$ & $\begin{array}{l}1 \\
5\end{array}$ & $\begin{array}{l}5 \\
25\end{array}$ & $\begin{array}{l}1 \\
5\end{array}$ & $\begin{array}{l}2 \\
10\end{array}$ & $\begin{array}{l}\mathbf{0} \\
\mathbf{0}\end{array}$ & $\begin{array}{l}0 \\
0\end{array}$ & $\begin{array}{l}18 \\
90 \%)\end{array}$ \\
\hline Total & 51 & $\begin{array}{l}16 \\
(31\end{array}$ & $\begin{array}{l}3 \\
6\end{array}$ & $\begin{array}{l}19 \\
37\end{array}$ & $\begin{array}{l}3 \\
6\end{array}$ & $\begin{array}{l}4 \\
8\end{array}$ & $\begin{array}{l}\mathbf{0} \\
\mathbf{0}\end{array}$ & $\begin{array}{l}2 \\
4\end{array}$ & $\begin{array}{l}47 \\
92 \%)\end{array}$ \\
\hline
\end{tabular}



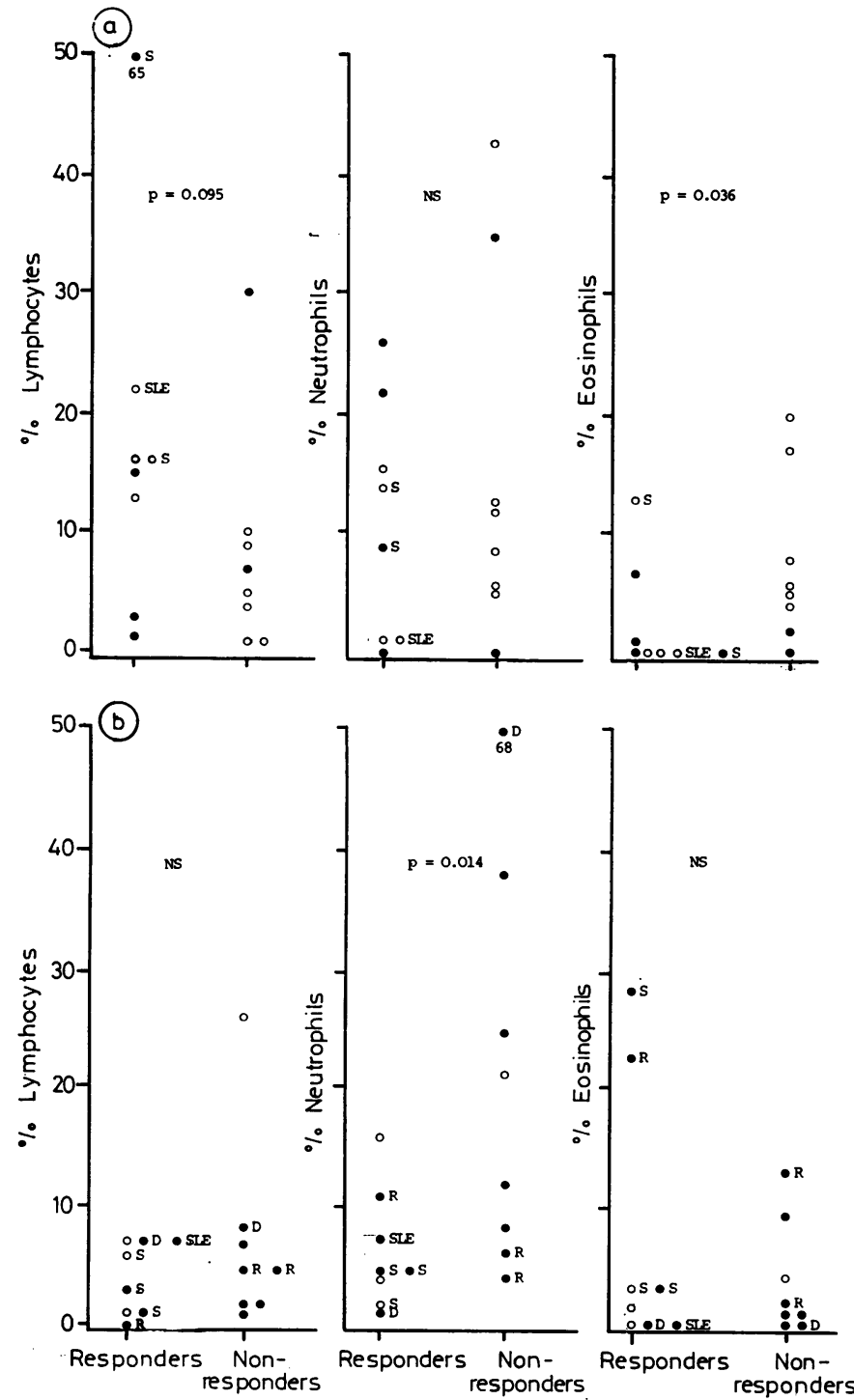

Fig 8 Relationship of lavage cell differential counts to response to treatment in patients with cryptogenic fibrosing alveolitis: (a) treatment with prednisone only, (b) therapeutic regimens: including other drugs by end of posttreatment follow-up period. Abbreviations and symbols as in fig 2.

Table 2 Relationship of profiles of lavage cell increases to response to treatment in CFA

\begin{tabular}{|c|c|c|c|c|c|c|c|}
\hline \multirow[t]{2}{*}{ Patients } & \multicolumn{6}{|c|}{ Number with increases in } & \multirow[b]{2}{*}{$\begin{array}{l}\text { Number } \\
\text { without } \\
\text { lavage cell } \\
\text { increases }\end{array}$} \\
\hline & $\begin{array}{l}\text { Neutrophils } \\
\text { only } \\
(>4 \%)\end{array}$ & $\begin{array}{l}\text { Eosinophils } \\
\text { only } \\
(>3 \%)\end{array}$ & $\begin{array}{l}\text { Neutrophils } \\
\text { and } \\
\text { eosinophils }\end{array}$ & $\begin{array}{l}\text { Lymphocytes } \\
\text { only } \\
(>11 \%)\end{array}$ & $\begin{array}{l}\text { Lymphocytes } \\
\text { and } \\
\text { neutrophils }\end{array}$ & $\begin{array}{l}\text { Lymphocytes, } \\
\text { neutrophils } \\
\text { and } \\
\text { eosinophils }\end{array}$ & \\
\hline \multicolumn{8}{|l|}{ * Response to prednisone } \\
\hline Responders 8 & 0 & $\mathbf{0}$ & 1 & 2 & 3 & 1 & 1 \\
\hline Non-responders 9 & 2 & $\mathbf{0}$ & 6 & 1 & 0 & $\mathbf{0}$ & 0 \\
\hline \multicolumn{8}{|l|}{ Response to other drugs } \\
\hline Responders 8 & 3 & $\mathbf{0}$ & 2 & 0 & $\mathbf{0}$ & $\mathbf{0}$ & 3 \\
\hline Non-responders 7 & 4 & 1 & 1 & $\mathbf{0}$ & $\mathbf{0}$ & 1 & $\mathbf{0}$ \\
\hline
\end{tabular}

* Differences in distribution of lavage cell profiles in responders (maintained improvement) compared with non-responders (no maintained improvement) significant at $\mathbf{p}=0.05$ using the Fisher Fourfold Table Test. 
neutrophils only (table 2). There were, however, significantly lower neutrophil levels (fig $8 \mathrm{~b}$ ) in the responders compared with the non-responders $(\mathrm{p}=$ 0.014). Response was achieved with the introduction of cyclophosphamide in six of the eight responders.

\section{Discussion}

The results of this study have confirmed the lung lavage findings of Reynolds et $a^{4}$ in CFA in several respects. Significantly lower lavage fluid recoveries have been confirmed in CFA by comparison with smoking control subjects without interstitial lung disease, and it has also been confirmed that lavage cell yields in smokers and non-smokers with CFA are similar to those in smoking control subjects. This contrasts with Reynolds and Newball's ${ }^{1}$ findings in normal healthy volunteers where lavage cell yields were three times higher in smokers than non-smokers and related to increased numbers of macrophages. These observations suggest increased lavage cell yields in non-smokers with CFA. It is, however, surprising that cell yields, and in particular macrophage yields, were not increased in smokers with CFA over smoking control subjects in view of the remarkably different histological appearance of normal and CFA lung.

Differential counting of lavage cells has, moreover, confirmed a significant smoking-independent trend towards lower percentages of macrophages in CFA compared with smoking control subjects reflecting significantly increased percentages of eosinophils and neutrophils, and our study has also demonstrated that lymphocytes are occasionally increased. As reported by others, ${ }^{12}$ eosinophils never exceeded $3 \%$ in control lavage of patients without interstitial lung disease. The contrasting increased range of eosinophils in CFA was, however, even higher than that observed by Reynolds and his colleagues. ${ }^{4}$ While we have confirmed a significant increase in neutrophils in CFA compared with control subjects, we differed from Reynolds and others ${ }^{2} 37$ in observing neutrophil counts exceeding $4 \%$ in occasional smoking control subjects. This emphasises a need for care in interpreting increased lavage neutrophil counts in smoking patients, which may sometimes reflect bronchial inflammation rather than acinar pathology. The high frequency of neutrophil increases in non-smokers as well as smokers with CFA does, however, imply the involvement of other stimulatory factors as well as smoking in this disorder.

The similarity of our bronchoalveolar lavage findings in patients with lone CFA and in those with associated systemic disease is important in view of the close similarity in their clinical features, natural history, and survival. ${ }^{9} 10$ However, lavage findings do differ in individual patients and two patients with associated dermatomyositis had very high neutrophil counts. Whether this is a characteristic finding awaits study of more patients.

The present study, unlike others, ${ }^{45}$ has not demonstrated lower lavage neutrophil counts in corticosteroid-treated compared with untreated CFA patients, although lower eosinophil counts were observed. In any event general changes in lavage cell counts after the introduction of therapy must not necessarily be equated with clinical response because only a small number of treated cases improve. Our study has, however, shown that lavage lymphocyte counts of higher than $11 \%$ predict cortiscosteroid response, while increases in eosinophils or neutrophils or both without associated lymphocyte increases predict failure to respond ( $p<0.05)$. However, among the small selected group of patients treated with cyclophosphamide or other non-steroid drugs or both, a few showed clinical improvement when the bronchoalveolar lavage had shown increases in eosinophils and/or neutrophils without lymphocyte increases. Lavage cell profiles may therefore have a value in guiding selection of therapy. Whether lavage cell levels might also be of value to monitor disease progression must await further follow-up.

Speculations on mechanisms contributing to tissue damage in CFA may now be entertained in view of the observations reported here. Of particular interest is the observation of the reduced proportion of macrophages containing smoking-related densely pigmented cytoplasmic inclusions in CFA smokers compared with smoking control subjects. In both, however, the features resembled smoking-related inclusions recognised by other workers. ${ }^{11^{-13}}$ The smaller numbers of smoking-related inclusions in CFA smokers may suggest some alteration in macrophage phagocytic function, or perhaps increased macrophage turnover reflecting inflammation. However, taking into consideration the recent observation of du Bois et $^{a^{14}}{ }^{14}$ of reduced macrophage lysosomal enzyme levels but increased lavage fluid levels in CFA compared with smoking control subjects, these findings may indicate an abnormal macrophage commitment to secretion rather than phagocytosis in CFA.

The very frequent neutrophil increases in CFA cannot be explained entirely by smoking or 
obvious bacterial infection. On the other hand, there is evidence that neutral proteases can split C5 to produce chemotactic fragments for neutrophils. ${ }^{15}$ Alveolar macrophages as well as neutrophils can produce neutral proteases when appropriately stimulated, ${ }^{16}$ and if production of chemotactic fragments should exceed their digestion by proteases, then this might start an inflammatory circuit characterised by influx of neutrophils. There is also evidence that alveolar macrophages from CFA patients directly secrete a neutrophil chemotactic factor. ${ }^{17}$ Evidence that human neutrophils release an eosinophilic chemotactic factor during phagocytosis ${ }^{18}$ might explain the associated influx of eosinophils. Circulating immune complexes have been demonstrated in high prevalence in $\mathrm{CFA}^{1920}$ and have recently been identified in lavage fluids. ${ }^{1721}$ Immune complexes can trigger direct release of neutrophil chemotactic factors from macrophages in vitro. ${ }^{17}$ They may also trigger local complement activation and the activation products $\mathrm{C} 3 \mathrm{a}$ and $\mathrm{C} 5 \mathrm{a}$ through their chemotactic activity may attract neutrophils and eosinophils. C3a and C5a acting as anaphylatoxins may also stimulate the release of eosinophil chemotactic factor from mast cells, and the finding of histamine in lavage fluids in cases with eosinophils ${ }^{22}$ provides some support for this. Whether there are separate explanations for neutrophil increases with and without associated eosinophil increases is not known. Features we have occasionally observed in CFA lavage eosinophils which are thought to relate to longevity or activation, are cytoplasmic vacuolation, Fc receptors for rabbit IgG, and morphological alteration of the crystalloid granules. ${ }^{22}$ These have been reported in tissue eosinophils but are very rare in normal blood eosinophils. ${ }^{23}$

The significance of our small increases in lavage lymphocytes are difficult to interpret in view of the absence of appropriate data in agematched non-smoking control subjects. However, the interest of this small minority is that they tend to respond to corticosteroids. Both $T$ and $B$ lymphocytes have been demonstrated in CFA lavage fluids but in proportions similar to those in blood, ${ }^{24}$ and this contrasts with the predominance of $T$ lymphocytes in lavages of sarcoidosis and hypersensitivity pneumonitis. ${ }^{4525}$ Observations suggestive of local B lymphocyte stimulation in CFA are the frequent presence of immunoglobulin-containing plasma cells, sometimes together with germinal follicles, in CFA lung biopsies ${ }^{26}$ and increased IgG: albumin ratios in CFA lavage fluids compared with blood. ${ }^{4}$ There is so far no evidence of activated
$\mathrm{T}$ lymphocytes in CFA lungs but $\mathrm{T}$ cells sensitised to collagen have been detected in the blood. ${ }^{27}$ Evidence of neutral protease production: from macrophages after stimulation with lympho $\overline{\bar{n}}$ kines $^{28}$ suggests that if lymphokines are present locally in some patients this may provide another? route to leucocyte chemotactic factor production.s

Current studies of bronchoalveolar lavage in $\overrightarrow{0}$ CFA are providing considerable information about the components of the inflammatory pros cess. This knowledge should now be applied to devise logical approaches to new forms of treatment.

We are grateful to the Medical Research Councit and the Tobacco Research Council for theiro continued support; to our many colleagues at the Brompton Hospital and Cardiothoracic Institute who helped in this project, to Miss Margaret Rehahn for statistical advice, and to Miss Heather Rolls and Mrs Pauline Hearn foro typing the manuscript.

\section{References}

1 Reynolds HY, Newball HH. Analysis of proteinsू and respiratory cells obtained from human lungs by bronchial lavage. J Lab Clin Med 1974; 84 559-73.

2 Daniele RP, Altose MD, Rowlands DT $\mathrm{Jr}_{5}^{3}$ Immunocompetent cells from the lower respiratory tract of normal human lungs. J Clin Invest 1975; 56:986-95.

3 Hinman LM, Stevens C, Matthay RA, Gee JBL 음 Angiotensin convertase activities in humanx alveolar macrophages: effects of cigarette smok ing and sarcoidosis. Science 1979; 205:202-3.

4 Reynolds HY, Fulmer JD, Kazmierowski JA尺 Roberts WC, Frank MM, Crystal RG. Analysis of cellular and protein content of broncho-alveolaro lavage fluid from patients with idiopathic pul? monary fibrosis and chronic hypersensitivit pneumonitis. J Clin Invest 1977; 59:165-75.

5 Weinberger SE, Kelman JA, Elson NA et al N Broncho-alveolar lavage in interstitial lung
disease. Ann Intern Med 1978; 89:459-66.

6 International Union Against Cancer. UICCW Cincinnati classification of the radiographico appearances of pneumoconioses. Chest $1970 ; 58_{0}$ 57-67.

7 Medical Research Council. Definition and clas£ sification of chronic bronchitis for clinical and epidemiological purposes. Lancet 1965; 1:775-9.

8 Cole PJ, Turton CWG, Lanyon HC, Collins JV $\frac{O}{\mathbb{D}}$ Broncho-alveolar lavage for the preparation of free lung cells: technique and complications. $B \Omega$ $J$ Dis Chest 1980; in press.

9 Turner-Warwick $M$, Burrows $B$, Johnson $A \stackrel{0}{\circ}$ Cryptogenic fibrosing alveolitis: clinical featureso 
and their influence on survival. Thorax 1980; 35:171-80.

10 Turner-Warwick $M$, Burrows B, Johnson A. Cryptogenic fibrosing alveolitis: response to corticosteroid treatment and its effect on survival. Thorax 1980; in press.

11 Pratt SA, Smith MH, Ladman AJ, Finley TN. The ultrastructure of alveolar macrophages from human cigarette smokers and non-smokers. Lab Invest 1971; 24:331-8.

12 Brody AR, Craighead JE. Cytoplasmic inclusions in pulmonary macrophages of cigarette smokers. Lab Invest 1975; 32:125-32.

13 Choux R, Viallat GPJ, Farisse P, Boutin C. Inorganic cytoplasmic inclusions in alveolar macrophages. The role of cigarette smoking. Arch Pathol Lab Med 1978; 102:79-83.

14 du Bois RM, Townsend PJ, Cole PJ. Alveolar macrophage lysozomal enzyme and $\mathrm{C} 3 \mathrm{~b}$ receptors in cryptogenic fibrosing alveolitis. Clin Exp Immunol 1980; in press.

15 Johnson U, Ohlsson K, Olsson I. Effects of neutral proteases on complement components. Scand J Immunol 1976; 5:421-6.

16 Horwitz AL, Kelman JA, Crystal RG. Activation of alveolar macrophage collagenase by a neutral protease secreted by the same cell. Nature 1976; 264:772-4.

17 Gadek J, Hunninghake G, Zimmerman R, Kelman J, Fulmer J, Crystal R. Pathogenic studies in idiopathic pulmonary fibrosis: control of neutrophil migration by immune complexes. Chest 1979; 75:264-5.

18 König W, Czarnetzki BM, Lichtenstein LM. Eosinophil chemotactic factor (ECF). II. Release from human polymorphonuclear leucocytes during phagocytosis. J Immunol 1976; 117:235-41.

19 Dreisin RB, Schwarz MI, Theofilopoulos AN, Stanford RE. Circulating immune complexes in the idiopathic interstitial pneumonias. $N$ Engl J Med 1978; 298:353-7.

20 Haslam PL, Thompson B, Mohammed I et al.
Circulating immune complexes in patients with cryptogenic fibrosing alveolitis. Clin Exp Immunol 1979; 37:381-90.

21 Haslam PL, Thompson B, Holborow EJ, TurnerWarwick M. A comparison of circulating immune complexes in patients with cryptogenic fibrosing alveolitis with bronchoalveolar lavage fluid findings and relationship with lavage inflammatory cell profiles and clinical course. In preparation, 1980.

22 Haslam PL, Dewar A, Cromwell O, TurnerWarwick M. Extended studies on eosinophils in bronchoalveolar lavage fluids from patients with cryptogenic fibrosing alveolitis: features suggesting "activation" and relationship with histamine levels. In preparation, 1980.

23 Tai PC, Spry CJF. Studies on blood eosinophils. 1. Patients with a transient eosinophilia. Clin Exp Immunol 1976; 24:415-22.

24 Hunninghake G, Gadek J, Weinberger S et al. Comparison of the alveolitis of sarcoidosis and idiopathic pulmonary fibrosis. Chest 1979; 75: supplement, 266-7.

25 Haslam PL, Lukoszek A, Turner-Warwick M. Bronchoalveolar lavage in interstitial lung disorders. III. Surface receptor studies of lavage cells and blood lymphocytes in patients with cryptogenic fibrosing alveolitis and sarcoidosis. In preparation, 1980.

26 Turner-Warwick M, Haslam PL, Weeks J. Antibodies in some chronic fibrosing lung diseases. II. Immunofluorescent studies. Clin Allergy 1971; 1:209-19.

27 Kravis TC, Ahmed A, Brown TE, Fulmer JD, Crystal RG. Pathogenic mechanisms in pulmonary fibrosis. Collagen-induced migration inhibition factor production and cytotoxicity mediated by lymphocytes. J Clin Invest 1976; 58:1223-32.

28 Wahl LM, Wahl SM, Mergenhagen SE, Martin GR. Collagenase production by lymphokineactivated macrophages. Science 1975; 187:261-3. 